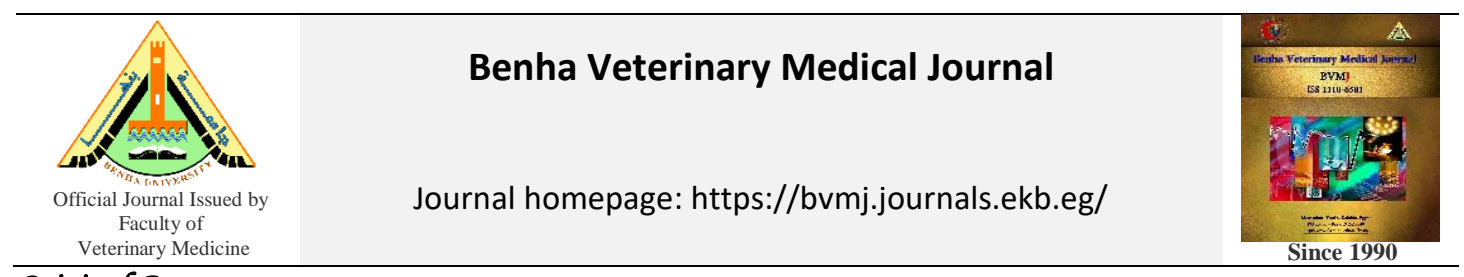

Original Paper

\title{
The potential anti-inflammatory effect of Omega-3 polyunsaturated fatty acids on experimentally induced ulcerative colitis in rats \\ Samy A. Hussein ${ }^{1}$, Mohamed B. Abd Elazem², Heba A Mostafa ${ }^{1}$ \\ ${ }^{1}$ Clinical Biochemistry Department, Faculty of Veterinary Medicine, Benha University, Egypt \\ ${ }^{2}$ Animal Health Research Institute, Zagazig Branch, Egypt
}

\begin{tabular}{|c|c|}
\hline ARTICLE INFO & ABSTRACT \\
\hline $\begin{array}{l}\text { Keywords } \\
\text { Caspase-3 } \\
\text { Inflammatory mediators } \\
\text { Omega-3 } \\
\text { Oxidative stress } \\
\text { Ulcerative colitis } \\
\text { Received } 18 / 06 / 2019 \\
\text { Accepted } 11 / 09 / 2019 \\
\text { Available On-Line } \\
\text { 12/05/2020 }\end{array}$ & 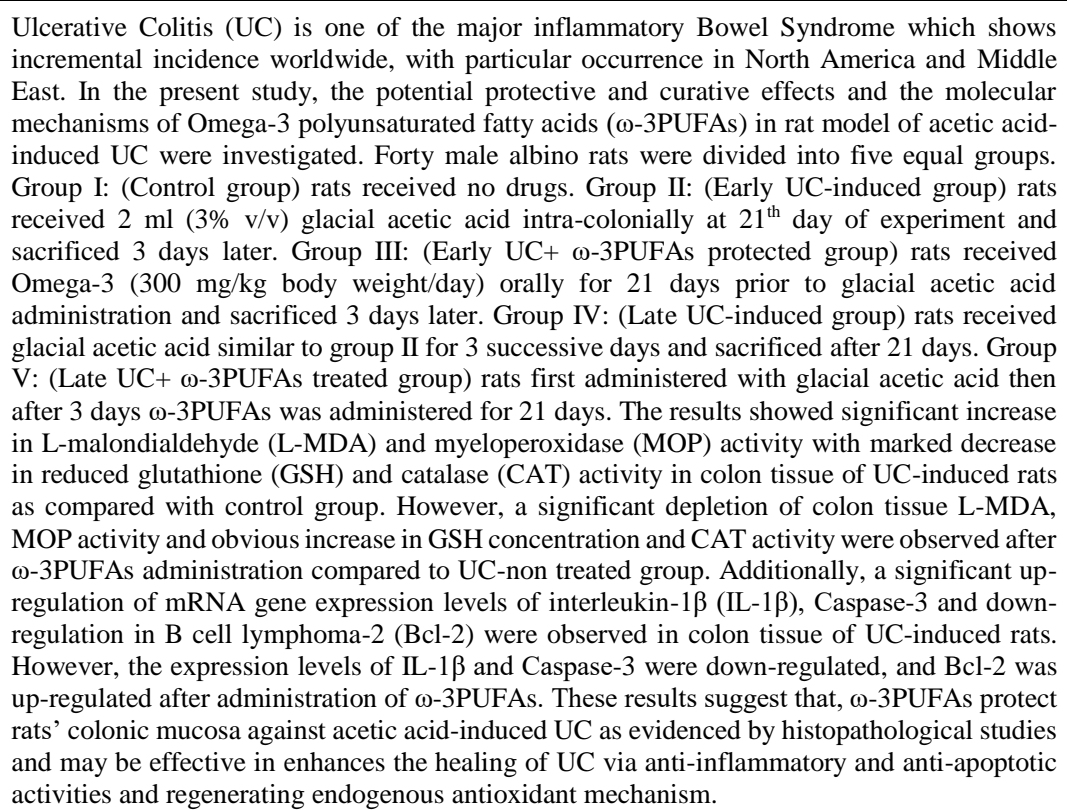 \\
\hline
\end{tabular}

\section{INTRODUCTION}

Inflammatory bowel disease (IBD) is a group of chronic frequent inflammatory disorders recognized by the development of intestinal inflammation produced from the transmural infiltration of neutrophils, macrophages, lymphocytes and mast cells, eventually giving rise to mucosal disruption and ulceration (Masoodi et al., 2013). IBD represents an increasing public health interest due to increasing incidence worldwide, according to recent reports, there is an increase in the global incidence of Ulcerative Colitis (UC). Currently, its propagation in Europe and North America is 24.3 and 19.2 per 100,000 individuals, respectively, and 6.3 per 100,000 people in Asia and Middle East. Most patients improve UC between the ages of 15 and 30 years, although individuals aged $50-70$ years consider as another prospect risk group (Molodecky et al., 2012). Ulcerative colitis is IBD in which the inflammation is in superficial layers of the intestinal mucosa, typically ascending in a continuous manner from the rectum and can expand to the whole colon (pancolitis). Clinical features of this disease are abdominal pain or cramping, diarrhea, fatigue, fever, weight loss and anorexia, loss of appetite and nutrients deficiency (Tatiya-aphiradee et al., 2017). Many components of the mucosal immune system are involved in the pathogenesis of IBD and contain intestinal epithelial cells, innate lymphoid cells, cells of the innate (macrophages/monocytes, neutrophils, and dendritic cells) and adaptive ( $\mathrm{T}$ - and B-cells) immune system, and their secreted mediators (cytokines and chemokines) (Wallace $e t$ al.,2014).

Acetic acid-induced colitis is usually utilized and easily an inducible model that is much like human IBD in terms of pathogenesis and inflammatory mediator profile (Hartmann et al., 2012).

MPO, a heme-containing peroxidase in myeloid cells (PMNs and monocytes), has a vital role in the expansion of the inflammatory response. A considerable growing in the

\footnotetext{
* Corresponding author: Prof. Samy A. Hussein Clinical Biochemistry Department, Faculty of Veterinary Medicine,

Benha University, Egypt
} 
activity of MPO in the colon tissues was recorded in acetic acid induced ulcerative colitis in rats which may reached to six-fold higher than normal (Rezayat et al., 2018). LMalondialdehyde (L-MDA), the end product of lipid peroxidation, is a good marker of free radical-mediated injury and oxidative stress (Ozturk et al., 2015). The concentration of serum MDA is elevated in colitis induced in rats by acetic acid. The lower concentration of antioxidants in the colitis group with additional increase in MDA and hydroperoxide levels which are indicator for the tissue injury.

Catalase is a key enzyme in the metabolism of hydrogen peroxide $\left(\mathrm{H}_{2} \mathrm{O}_{2}\right)$ and reactive nitrogen species, and its expression and localization is significantly change in this diseases (Glorieux and Calderon, 2017). Because of the importance of excess and uncontrollable Reactive Oxygen Species (ROS) in the pathogenesis of ulcerative colitis, the value to determine free radical scavenger such as reduced Glutathione. The endogenous antioxidant GSH was reduced significantly in the colonic tissues of the acetic acid-induced ulcerative colitis in rats (Karakoyun et al., 2018).

Colon Caspase-3 levels were higher in the colitis than in the control group rats (Akcan et al., 2008). Caspases (cysteine aspartic acid proteases) are a family of cysteine proteases that have vital roles in apoptosis, development and inflammation (Martnon et al., 2009). Caspase-3 has an important function in this cascade, via activation of cytoplasmic DNase, which in turn migrates to the nucleus and fragments the DNA. So, DNA fragmentation especially when it is inter-nucleosomal is one of the gold standards for detection of apoptosis, therefore, Colon caspase-3 levels were higher in the colitis than in the control group rats. The B-cell lymphoma-2 (Bcl-2) family of proteins are key regulators of programmed cell death (Chipuk et al., 2010). They minimized mitochondrial membrane permeability and inhibit the release of cytochrome $\mathrm{C}$ into the cytoplasm (Orrenius et al., 2007). Studies indicate that an increment in Bcl-2 level in acetic acid induced ulcerative colitis in rats when measured immunohistochemically (Aksit et al., 2016). Cytokines are small signal molecules, released by immune cells, facilitate communication between cells. Cytokines increase or down regulate different cell types in an autocrine or paracrine way, Cytokines can be functionally divided into pro-inflammatory, such as IL-1 $\beta$, tumor necrosis factor (TNF)- $\alpha$ and IL-6, and anti-inflammatory, like IL-10 and transforming growth factor (TGF)- $\beta$ (Sanchez-Muñoz et al., 2008 ). IL-1 $\beta$ secreted from activated macrophages activates formation of other cytokines, arachidonic acid metabolites, and proteases by intestinal macrophages, neutrophils, smooth muscle cells, fibroblast, and epithelial cells. A key role of IL-1 $\beta$ is its ability to stimulateIL-2 and IL-2 receptor on $\mathrm{T}$ lymphocytes, IL-1 $\beta$ appears to be a stimulator of diarrhea, the major symptom of intestinal inflammation. Eicosapentaenoic acid (EPA) and docosahexaenoic acid (DHA) are the most effective

Omega-3 ( $n-3)$ fatty acids found in oily fish and fish oil supplements. These fatty acids are able to partly inhibit a number of aspects of inflammation including leukocyte chemotaxis, adhesion molecule expression and leukocyteendothelial adhesive interactions, production of eicosanoids like prostaglandins and leukotrienes from the Omega-6 (n-6) fatty acid arachidonic acid, production of inflammatory cytokines, and T-helper 1 lymphocyte reactivity (Calder, 2015). Among the possible mechanisms underlying the anti-inflammatory effects of omega-3 PUFAs are the diversion of eicosanoid synthesis to noninflammatory products, the production of anti-inflammatory lipid mediators (resolvins and protectins), the inhibition of nuclear factor $\varkappa \mathrm{B}(\mathrm{NF}-\varkappa \mathrm{B})$ activation, and the induction of peroxisome proliferator activated Receptor- $\gamma$ (PPAR- $\gamma$ ) synthesis in dendritic cells (Yates et al., 2014). Both animal and clinical work suggest that omega 3-fatty acids are antiinflammatory in their action and so have the potential to be of use in the treatment of inflammatory bowel disease (IBD) (Farrukh and Mayberry, 2014). Accordingly, the purpose of the present study was to investigate the effect of Omega-3 against acetic acid induced colitis in rats. Also, to determine whether Omega-3 when administered to ulcerative colitis induced-rats would attenuate the oxidative stress in colon tissue, beneficial for prevention and treatment of colitis complications.

\section{MATERIAL AND METHODS}

\subsection{Experimental animals}

Forty male albino rats, 12-16 weeks old and average body weight 220-250 g were used in the experimental assessment of this study. Rats were obtained from Laboratory Animals Research Center, Faculty of Veterinary Medicine, Benha University. Animals were kept in individual metal cages, and fresh and clean drinking water was supplied ad-libitum. Rats were kept at constant environmental and nutritional conditions during the period of experiment. The animals were kept 14 days for acclimatization before the beginning of the experiment.

\subsection{Chemicals and drugs:}

The chemicals and drugs used in the present study were: Omega-3 (fish oil) fatty acids (Puritan's Pride, INC. Holbrook, NY 11741, U.S.A). Omega-3 fatty acids present in a soft gelatin capsulated form with $1360 \mathrm{mg}$ in each capsule. Ester-omega fish oil $1360 \mathrm{mg}$ provides $950 \mathrm{mg}$ of total fatty acids comprising of Eicosapentaenoic acid (EPA) $625 \mathrm{mg}$, Docosahexaenoic acid (DHA) $244 \mathrm{mg}$ and other fatty acids. Omega-3 fatty acids were dissolved in propylene glycol and administered orally in a daily dose of $300 \mathrm{mg} / \mathrm{kg}$ body weight using stomach tube. Dose of omega-3 fatty acids was chosen to be within the therapeutic range levels reported in the pamphlet according to (Paget and Barnes, 1964).

Glacial acetic acid was manufactured by Merck Millipore, Darmstadt, Germany.

\subsection{Induction of ulcerative colitis:}

After 36 hours of fasting, the rats were anesthetized by intraperitoneal injection of sodium thiopental $(500 \mathrm{mg}$ dissolved in $12.5 \mathrm{ml}$ of normal saline) at the dose level of 0.2 $\mathrm{ml} / 200 \mathrm{gm}$ body weight $(40 \mathrm{mg} / \mathrm{kg}$ b.wt i.p.). To induce colitis, the rats were intra-colonially treated with $3 \mathrm{ml}$ of (3\% $\mathrm{v} / \mathrm{v})$ glacial acetic acid via a cannula that was placed $8 \mathrm{~cm}$ proximal to the anus using a rectally inserted flexible polyethylene catheter. Rats were positioned head-down for 2-3 minutes to preclude immediate anal leakage of the instillate and thereafter returned to their cages with access to food and water ad libitum. Also, $0.5 \mathrm{ml}$ physiological saline was intra-colonially administered to the rats in the control group via a cannula according to(MacPherson and Pfeiffer, 1978). 


\subsection{Experimental design:}

Rats were randomly divided into five main equal groups, 8 rats each, placed in individual cages and classified as follow:

- Group I:(Control Normal group): Rats received no drugs, served as control non-treated for all experimental groups.

- Group П:(Early Ulcerative colitis-induced group): Rats received glacial acetic acid $(2 \mathrm{ml} / \mathrm{rat})$ at first day of experiment for 3 successive days, and the rats were sacrificed after 21 days from induction.

- Group III : (Early Ulcerative colitis+ Omega-3 protected group):Rats received Omega-3 (300 mg /kg b.wt) orally for 21 days, then ulcerative colitis was induced by $3 \%$ acetic acid ( $(v / v)$ on day $21^{\text {th }}$ for 3 successive days and on day $24^{\text {th }}$ the animals were sacrificed and the samples were taken.

- Group IV:(Late Ulcerative colitis - induced group): Rats received glacial acetic acid $(2 \mathrm{ml} / \mathrm{rat})$ at first day of experiment for 3 successive days, and the rats were sacrificed after 21 days from ulcerative colitis-induction.

- Group V:(Late Ulcerative colitis + Omega-3 treated group): in this group the ulcerative colitis was induced in rats by $3 \%$ acetic acid (v/v) for 3 successive days, then rats received Omega-3 (300 mg $/ \mathrm{kg}$ b.wt) orally for 21 days, and on day $24^{\text {th }}$ the animals were sacrificed and the samples were taken.

\section{5. Sampling:}

Colonic tissue specimen was collected at the end of experiment on day $24^{\text {th }}$ for all animal groups (control and experimental groups).

2.5.1. Colon tissue for biochemical analysis.

After 21 days of treatment with Omega-3 the rats of each group were sacrificed by cervical decapitation. The abdomen was opened and the colon specimen was quickly removed and opened using a scrapper gently, cleaned by rinsing with ice-cold isotonic saline to get rid of any blood cells, clots and scraps of food, then but it between 2 filter papers and quickly stored in a deep freezer at $\left(-20{ }^{\circ} \mathrm{C}\right)$ for further biochemical analysis. Briefly, colon tissues were divided into appropriate portions, homogenized with a glass homogenizer in 9 volume of ice-cold $0.05 \mathrm{mM}$ potassium phosphate buffer (pH7.4) to make $10 \%$ homogenates. The homogenates were centrifuged at $6000 \mathrm{rpm}$ for $15 \mathrm{~min}$ at 4 ${ }^{\circ} \mathrm{C}$ then the resultant supernatant were used for the determination of Myeloperoxidase (MPO), LMalondialdehyde (L-MDA) and Catalase (CAT). Also, 0.2 $\mathrm{gm}$ of colon tissues were minced into small pieces homogenized with a glass homogenizer in $0.4 \mathrm{ml}$ of $25 \%$ metaphosphoric acid (MPA) (ref. No.: 253-433-4, SigmaAldrich, Germany), then $1.4 \mathrm{~mL}$ of distilled water was added, mixed and incubated for 1 hour and centrifuged for $10 \mathrm{~min}$ at $3000 \mathrm{rpm}$ then the clean supernatant was removed and used for determination of GSH concentration.

2.5.2. Colonic tissue for molecular analysis

At the end of experiment, and following sacrificing by decapitation, rats' colon tissue were immediately excised and frozen in liquid nitrogen and then stored at $-80{ }^{\circ} \mathrm{C}$ until used for RNA extraction for determination of IL-1 $\beta$, Caspase- 3 and Bcl-2 gene expression analysis by qPCR . 2.5.3. Colon tissue for histopathological examination

Colon tissue specimens were taken from different parts of the colon for histopathological examination. The specimens were preserved in $10 \%$ buffered neutral formalin. The fixed tissue was rinsed in tap water, dehydrated through graded series of alcohols, cleared in xylene and embedded in paraffin wax. $5 \mu \mathrm{m}$ thick sections were cut and stained with hematoxylin and eosin (H\&E) (Bancroft and Stevens, 1996) and then the tissues were examined and evaluated by light microscopy.

\subsection{Analysis:}

2.6.1. Biochemical analysis:

Colonic tissue L-malondialdehyde (L-MDA), Catalase (CAT), reduced glutathione (GSH) and Myeloperoxidase (MPO) were determined according to the methods described by Mesbah et al. (2004), Xu et al. (1997), Patterson and Lazarow (1955), Shi et al. (2005), and Qiu et al. (2015), respectively.

2.6.2. Molecular analysis:

RNA was isolated from colon tissue of rats using RNeasy Mini Kit (Thermo Qiagen, \#74104) according to the manufacturer's protocol. Following determination of RNA concentration and purity by Quawell nanodrop Q5000 (USA), $5 \mathrm{mg}$ of total RNA from each sample was reverse transcribed using Quant script reverse transcriptase. The produced cDNA was used as a template to determine the relative expression of Caspase-3,BCl-2 and IL-1 $\beta$ using Step One Plus real time PCR system (Applied Biosystem, USA) and gene specific primers. The reference gene, $\beta$ actin, was used to calculate fold change in target genes expression. The thermal cycling conditions, melting curves temperatures, and calculation of relative expression was done. For the treated groups, assessment of $2^{-\Delta \Delta \mathrm{Ct}}$ determined the fold change in gene expression relative to the control.

\begin{tabular}{lcc}
\multicolumn{3}{l}{ Forward and reverse primers sequence for real time PCR. } \\
\hline Gene & Forward primer $(/ 5-----/ 3)$ & Reverse primer $(/ 5$------ /3) \\
\hline Caspase3 & GGTATTGAGACAGACAGTGG & CATGGGATCTGTTCTTTGC \\
Bcl-2 & AGTACCTGAACCGGCATCTG & CATGCTGGGGCCATATAGTT \\
IL-1 $\beta$ & CACCTCTCAAGCAGAGCACAG & GGGTTCCATGGTGAAGTCAAC \\
$\beta$-actin & ACCCACACTGTGCCCATCTA & CGTCACACTTCATGATG \\
\hline
\end{tabular}

\subsection{Statistical Analysis}

For biochemical analysis, the obtained data were analyzed and graphically represented using the statistical package for social science (SPSS, 13.0 software, 2009), for obtaining mean and standard deviation and error. The data were analyzed using one-way ANOVA to determine the statistical significance of differences between groups. Duncan's test was used for making a multiple comparison between groups for testing the inter-grouping homogeneity. However, for molecular analysis the difference between the groups was determined by One-way ANOVA using Graph Pad Prism 5 (Graph Pad Software, Inc., LaJolla, CA, USA). Comparison of means was carried out with Tukey's Honestly Significant Difference (Tukey's HSD) test. Data were presented as mean SEM (standard error of mean) and significance was declared at $\mathrm{P}<0.05$

\section{RESULTS}

Effect of Omega-3 administration on colon tissue L-MDA, CAT, GSH and MPO of acetic acid-induced ulcerative colitis in male rats is presented in table (1). The obtained results showed significant increase in L-MDA concentration and MPO activity with marked decrease in CAT activity and GSH concentrations in colon of acetic acid -induced 
ulcerative colitis in rats as compared with control normal group. However, a significant depletion of colon tissue LMDA, MPO activity and marked increase in CAT activity and GSH concentration were observed after omega-3 administration compared to colitis untreated rats.

Effect of Omega-3 administration on the relative mRNA expression of IL-1 $\beta$, Caspase- 3 and Bcl-2 in colon of acetic acid -induced ulcerative colitis in rats is shown in table (2). The obtained qPCR results revealed a significant up- regulation of IL-1 $\beta$ and Caspase- 3 and a significant downregulation of $\mathrm{Bcl}-2$ gene expression levels in colon of acetic acid-induced ulcerative colitis in rats (G2 and G4) as compared to control normal group (G1). This expression was significantly down-regulated with significant up-regulation in Bcl-2 in colon tissues following administration of Omega3either before (G2) or after (G4) induction of UC, with lower expression in preventive group $(\mathrm{G} 3)$.

\begin{tabular}{|c|c|c|c|c|}
\hline Parameters Animal groups & MPO (U/mg. tissue) & L-MDA (n mol/g. tissue) & CAT (m mole/min/g. tissue) & GSH (n g/g. tissue) \\
\hline Group I: Normal control & $0.07 \pm 0.001^{\mathrm{e}}$ & $23.86 \pm 0.89^{\mathrm{d}}$ & $111.50 \pm 5.11^{\mathrm{a}}$ & $12.58 \pm 0.64^{\mathrm{a}}$ \\
\hline Group $\Pi$ : (early UC-induced group) & $0.50 \pm 0.030^{\mathrm{b}}$ & $83.25 \pm 2.43^{\mathrm{b}}$ & $19.28 \pm 1.010^{\mathrm{d}}$ & $1.00 \pm 0.040^{\mathrm{d}}$ \\
\hline Group III: (early UC+ Omega 3 protected group) & $0.18 \pm 0.01^{\mathrm{d}}$ & $44.56 \pm 1.22^{\mathrm{d}}$ & $62.46 \pm 3.05^{\mathrm{b}}$ & $5.19 \pm 0.27^{\mathrm{b}}$ \\
\hline Group IV: (late UC-induced group) & $0.67 \pm 0.03^{\mathrm{a}}$ & $95.36 \pm 2.60^{\mathrm{a}}$ & $12.61 \pm 0.94^{\mathrm{e}}$ & $0.45 \pm 0.02^{\mathrm{e}}$ \\
\hline Group V: (late UC+ Omega-3treated group) & $0.27 \pm 0.02^{\mathrm{c}}$ & $51.42 \pm 1.47^{\mathrm{c}}$ & $31.87 \pm 2.13^{\mathrm{c}}$ & $1.91 \pm 0.11^{\mathrm{c}}$ \\
\hline
\end{tabular}

Table 2 Effect of omega- 3 administration on the relative expression of capase-3, Bcl-2 and IL-1 $\beta$ gene in colon tissue of acetic

\begin{tabular}{lllllll} 
acid -induced ulcerative colitis in male rats. & \multicolumn{7}{c}{ Caspase- 3} & Bcl-2 & IL-1 $\beta$ \\
\hline Animal groups & Fold change mean & SEM & Fold change mean & SEM & Fold change mean & SEM \\
\hline Group I: Normal control & $1.00^{\mathrm{c}}$ & 0.09 & $1.00^{\mathrm{a}}$ & 0.05 & $1.00^{\mathrm{d}}$ & 0.09 \\
Group П: (early UC-induced group) & $5.57^{\mathrm{b}}$ & 0.47 & $0.20^{\mathrm{d}}$ & 0.01 & $8.75^{\mathrm{b}}$ & 0.38 \\
Group III: (early UC+ Omega 3 protected group) & $3.86^{\mathrm{d}}$ & 0.19 & $0.59^{\mathrm{b}}$ & 0.04 & $5.06^{\mathrm{c}}$ & 0.27 \\
Group IV: (late UC-induced group) & $10.70^{\mathrm{a}}$ & 0.52 & $0.18^{\mathrm{d}}$ & 0.01 & $10.48^{\mathrm{a}}$ & 0.42 \\
Group V : (late UC+ Omega-3 treated group) & $6.73^{\mathrm{c}}$ & 0.38 & $0.39^{\mathrm{c}}$ & 0.03 & $4.92^{\mathrm{c}}$ & 0.28 \\
\hline Means within the same column carrying different superscript letters are significantly different (P< 0.05$)$ & & &
\end{tabular}
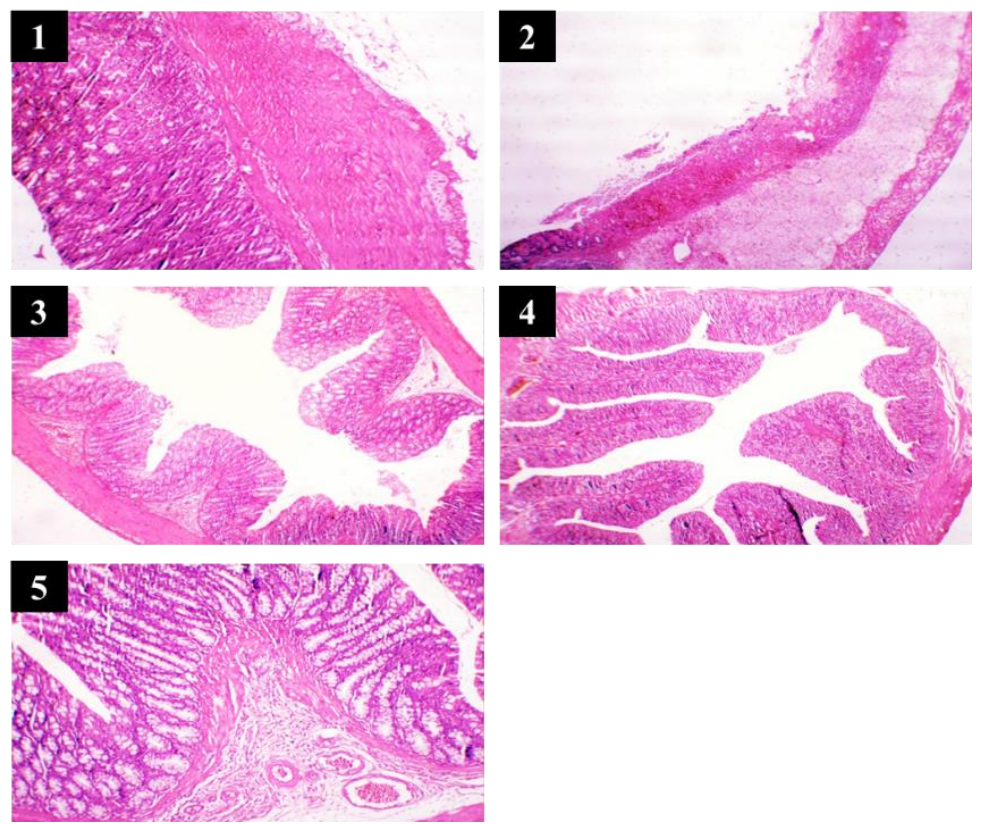

Fig 1 Represent (Group I) Normal control Colon, showing normal histological appearance of mucosal epithelium, submucosa and muscle layer. H\&E stain x 200. Fig 2 Represent (Group П) early UC-induced, showing mucosal ulcer characterized by marked loss of normal mucosal architecture with replacement by a thick coagulum of necrotic debris,

fibrin and hemorrhage. H\&E stain x 100 .
Fig 3 Represent (Group III) early UC+ Omega 3 protected group, showing multifocal areas of erosions in colonic mucosa. H\&E stain x 40 .

Fig 4 Represent (Group IV) late UC-induced group), showing thick mucosa characterized by elevated and hyperplasic, tortuous crypts; while thin area revealed blunted crypts and decrease in number of goblet cells. H\&E stain $\mathrm{x} 40$.

Fig 5 Represent (Group V) late UC+ Omega-3 treated group, showing marked thickening of the mucosa characterized by elevated and hyperplastic, tortuous crypts with increase in numbers of goblet cells. H\&E stain x 200 .

\section{DISCUSSION}

Inflammatory bowel diseases (IBD) is classified into two diseases are ulcerative colitis (UC) and Crohn's disease (CD) are multi-factorial, relapsing disorders of the gastrointestinal tract. Although, the etiology of these diseases involves altered immune responses, epithelial dysfunction, environmental factors, and nutrition (Banerjee et al.,2019).Ulcerative colitis is characterized by intestinal mucosa inflammation with an extension from the rectum to 
the colon in a uniform manner (Hosseinzadeh et al.,2017).the present study, the experimental induction of colitis with instillation of $3 \mathrm{ml}$ of $3 \%$ acetic acid into the colon was successfully achieved and confirmed by macroscopic damage and histopathological findings such as congestion, haemorrhages, edema, and leukocytic infiltration. This result is in agreement with previous reports in animal models of colitis, which demonstrated similar macroscopic and microscopic pictures and tissue damage after the induction of colitis using acetic acid (El-Akabawy and El-Sherif , 2019). The use of acetic acid for the production of ulcerative colitis in rats is a standardized model, and it has been reported to have similar histological features to that of human. It is usually associated with deep ulceration and inflammation, enhanced vasopermeability as well as severe influx of neutrophils and macrophages to the site of injury (Kandhare et al.,2016).

Michalak et al. (2016) reported that polyunsaturated fatty acids (PUFAs) are bioactive lipids which regulate inflammation and immunity. They had increased importance in nutritional therapy and are recommended dietary supplements. Gastrointestinal diseases are one of the diseases that ameliorate through the administration of (PUSFA). Lipid mediators, such as prostaglandins and leukotrienes play pivotal roles in the initiation of acute inflammation, where as resolvins and protectins, inflammation mediators derived from long chain poly unsaturated fatty acids omega-3 (LC-PUFA n-3) (Serhan $e t$ al., 2015), promote and stimulate the active resolution of inflammation. the control of neutrophil infiltration is most interest in this situation, which underlines the importance of resolvins and protectins omega-3 lipid mediators; resolution of acute inflammation is a central component of host defense and the return of tissue to homeostasis (Serhan et al., 2015). In the current study of Myeloperoxidase MPO, a glycosylated hemo protein enzyme in the granules of neutrophils and monocytes. It is an important enzyme used during phagocytic lysis of engulfed foreign particles which takes part in the defense of the organism, MPO also modulates inflammation by generating ROS (Bastaki et al., 2016). The activity of this enzyme is used as an indirect measurement for the severity of tissue damage (Klebanoff $e t$ al., 2013).

Increasing in activity of MPO is often observed in inflammatory gastrointestinal disorders ,In present study, MPO was up regulated in the acetic acid-induced ulcerative colitis according to (Bastaki et al., 2016; Kumar et al., 2019), and significantly down-regulated after administration of Omega-3 both as a protection or treatment to acetic acid -induced ulcerative colitis in rats ,although it not reach the normal values as reported in (Soliman et al .,2010; Tyagi et al., 2012), decreasing of MPO activity after Omega-3 administration , may be due to effect of Eicosapentaenoic acid EPA-derived 18-hydroxyeicosapentaenoic acid (18HEPE) and 15-hydroxyeicosapentaenoic (15-HEPE) each produced by hypoxic vascular endothelial cells and show some activity in reducing polymorphic macrophage neutrophil (PMN) trans-endothelial migration and thus decreasing Myeloperoxidase activity as reported in (Marcon et al., 2013; Serhan et al., 2018). Hamabata et al. (2018) suggested that treatment with the n-3 fatty acid-derived lipid mediator, resolvin D1/D2, decreased neutrophile activity and resulted in the amelioration of the symptoms of Dextran
Sulfate Sodium (DSS)-and Trinitrobenzene Sulfonic Acid (TNBS)-induced colitis in mice.

Lipid mediators derived from EPA and Docosahexaenoic acid (DHA) have an important role in stopping the inflammation cascade as explained by (Bannenberg and Serhan, 2010; Balas et al.,2014). Resolving E1, resolvin D1 and protectin D1 all inhibited trans-endothelial migration of neutrophils, so preventing the infiltration of neutrophils into the sites of inflammation; resolvin D1 inhibited interleukin- $1 \beta$ IL-1 $\beta$ production; and protectin D1 inhibited tumor necrosis factor $\alpha(\mathrm{TNF}-\alpha)$ and (IL-1 $\beta$ ) production.

Oxidative stress Biomarkers (Malonaldehyde MDA, Catalase CAT, reduced glutathione GSH) Oxidative stress plays vital role in the progression of the disease. Oxidative stress induces and triggers IBD through two pathways, including oxidative injury to intestinal mucosal cells and up regulation of inflammatory cytokines (Khodayar et al., 2018). Acetic acid causes severe oxidative stress in colonic tissue, which is manifested as an enhancement in lipid peroxidation that occurs via an increase in the L-MDA content ; also this sever oxidative stress leads to the consumption of GSH and decreasing its content in colonic tissue as well as decreasing CAT activity in tissue, simply GSH and CAT trying to scavenge the free radicals from cells to ameliorating the happening oxidative stress that can be destruct the cells and to return Redox balance to our cells ; this evidence is reported (Dogan et al., 2014; Tekeli et al., 2018; Soliman et al., 2019).In current study we found that decreasing in L-MDA and increasing in both CAT activity and GSH concentration were happened also due to the administration of Omega-3; this result is agreed with other previous studies(Tyagi et al., 2012) which improve the antioxidant activity of Omega-3.EPA was discovered as a precursor of resolvin E1 and resolvin E2; lipid mediators with potent resolution and anti-oxidant effects as reported in (Soliman et al .,2010; Sharma et al., 2019). Apoptosis is a programmed cell death process involved in the normal turnover of damaged cells (Shalkami et al.,2018). Apoptosis also considered as a component of a defense mechanism triggered during tissue damage and immune reactions caused by many pathological conditions (Ola et al., 2011). Caspase subfamilies are divided into initiator caspases (initiate apoptosis) includes the Caspase-8, -9 , and -10 and the effectors caspases include Caspases -3,-6,-7 (Salmena et al., 2003).

Kountouras (2003) during the process of death by apoptosis, the cell shrinks, its mitochondria break down with the release of cytochrome c (Cyt c), it develops bubble-like blebs on its surface, the chromatin (DNA and protein) in its nucleus degrades and breaks into small, membranewrapped, fragments (apoptotic bodies). Consequently, the phospholipid phosphatidyl serine, which is normally hidden within the plasma membrane, is exposed on the cell surface, and is then bound by receptors on phagocytic cells (macrophages and dendritic cells) which then engulf the cell fragments. Lastly, the phagocytic cells secrete cytokines that inhibit inflammation. Caspase- 3 has a central role in this cascade, and is known to activate cytoplasmic DNase, which subsequently migrates to the nucleus and fragments the DNA. Therefore, DNA fragmentation particularly when it is inter-nucleosomal is one of the gold standards for detection of apoptosis. Akcan et al., (2008) suggested that, Colon Caspase-3 levels were higher in the colitis than in the control group rats. B cell lymphoma (Bcl-2) proteins are the key 
regulators of the intrinsic apoptosis pathway. Each member of this family contains one or more BCL-2 homology (BH) domains, $\mathrm{BH} 1-\mathrm{BH} 4$. Apoptosis is triggered by proapoptotic, $\mathrm{BH} 3$-only proteins, the name of which stems from the fact that these proteins contain only a single BH domain, in this case, BH3. The key effectors of apoptosis commitment are BH3-only 'activator' proteins (Singh et al.,2019).Proteins of the Bcl-2 family are regulated by multiple mechanisms , and their expression levels differ widely depending on tissue type, cell lineage, developmental stage, organismal age and any stress or damage that is experienced as described by (Sarosiek et al.,2017). Dysregulation of apoptosis recognized as a pivotal key in the pathogenesis of UC. this dys-regulation involved two ways up-regulation of pro-apoptotic genes like Caspase-3 and down- regulation of anti-apoptotic genes like Bcl-2 this concept is agreed with our findings that acetic acid significantly induced epithelial apoptosis in colon; the administration of acetic acid resulted in an increased expression of caspase-3, which is specified as an apoptotic marker as reported in (Labib et al.,2016; Ghalwash et al ., 2017; Shalkami et al .,2018; Saber et al., 2019; El-Akabawy and El-Sherif ., 2019) and decreasing in expression of BCL2 as reported in (Saber et al., 2019; Aksit et al.,2016).In the acetic acid group, Caspase-3 protein expression was upregulated This can be explained by the results of (Labib et $a l ., 2016)$ who reported that binding of TNF- $\alpha$ to its receptors activates receptor-dependent pathways of apoptosis through activation of caspases including Caspase-3. A number of studies suggest that N-3 PUFAs exert beneficial biological functions in carcinogenic processes. In vitro studies have reported that EPA and DHA induced apoptosis in the colon cancer cell lines HT-29, Caco-2, and DLD-1 through an increase in caspase-3 activity and inhibition of Bcl-2. Cytokines are associated with inflammatory diseases, with higher levels of TNF, IL-1 $\beta$, interleukin-6 (IL-6), and interleukin-8 (IL-8) being a common feature of many inflammatory conditions (Calder et al.,2013).Various studies have shown that acetic acid-induced colitis resemble acute human intestinal inflammation by stimulating the production of inflammatory mediators this evidence is reported in (Boobalan et al.,2015; Hosseini et al.,2017). In this study the administration of Omega-3 significantly down-regulate pro inflammatory cytokine IL-1 $\beta$ gene expression level, our findings is supported by other previous studies on human (Calder, 2015; Diab et al.,2018) and previous studies on animal (Triantafyllidis et al.,2015; Serhan et al., 2018). Calder (2017) suggested that EPA and DHA give rise to anti-inflammatory and inflammation resolving mediators called resolvins, protectins, and maresins. Mechanisms underlying the anti-inflammatory actions of EPA and DHA include altered cell membrane phospholipid fatty acid composition, disruption of lipid rafts, inhibition of activation of the pro-inflammatory transcription factor nuclear factor $x \mathrm{~B}$ so reducing expression of inflammatory genes and activation of the antiinflammatory transcription factor peroxisome proliferatoractivated receptor $\gamma$. Marion-Letellier et al. (2015) reported in his review that The transcription factor NF- $x \mathrm{~B}$ is sequestrated in the cytosol linked to its inhibitory protein I $x \mathrm{~B}$. Upon stimulation, $\mathrm{I} x \mathrm{~B}$ is phosphorylated and then degraded into the proteasome. Free NF- $\varkappa$ B translocates to the nucleus and activates the gene expression of proinflammatory targets. Numerous studies have observed that n-3 PUFA can inhibit NF- $x$ B pathway in inflammatory conditions. Omega-3 PUFA themselves are also ligands that directly bind to nuclear receptors that impact on gene expression. Feeding fish oil to mice decreased the production of TNF, IL-1 $\beta$, and IL- 6 by endotoxin-stimulated macrophages and decreased circulating TNF, IL-1 $\beta$ and IL6 concentrations in mice injected with endotoxin. Some animal studies as (Sierra et al., 2008) report that marine n-3 fatty acids increase the concentration of the antiinflammatory cytokine interleukin 10 (IL-10). Several studies providing marine $\mathrm{n}-3$ fatty acid supplements to colitis-induced animals have reported decreased production of TNF, IL- $1 \beta$ and IL- 6 by endotoxin stimulated monocytes or mononuclear cells (Cho et al.,2011).It has been shown that in cell culture pretreatment with EPA and DHA decreases lipopolysaccharide-stimulated THP-1 macrophage TNF $\alpha$, IL-1b and IL-6 production compared with control cells (Weldon et al.,2007) which evidence the protective effect of omega-3 against inflammation .Several studies providing marine $n-3$ fatty acid supplements to colitis-induced animals have reported decreased production of TNF, IL- $1 \beta$ and IL- 6 by endotoxin stimulated monocytes or mononuclear cells (Marcon et al., 2013).

the histological changes due to acetic acid were vivid. They included massive haemorrhage, complete absence of epithelial lining on the mucosal surface, severely damaged villi and crypts with subsequent loss of their architecture except in a few crypts, depletion of goblet cells, and severe infiltration of inflammatory cells. Acetic acid has been documented to induce localized inflammation and loss of mucosal integrity leading to epithelial injury. Omega-3 administration in groups 3 and 5 in this work resulted in significant increase in goblet cells containing acidic mucins, reflecting higher degree of mucins maturation. This may be attributed to stimulation of goblet cell via prostaglandin, which in turn activates synthesis and secretion of glycoproteins. This altered mucin maturation could be due to accelerated efflux of immature mucins in response to acetic acid administration as reported by Soliman etal.,2010.

\section{CONCULSION}

These findings suggested that oral treatment with Omega-3 shows a significant protective effect in acetic acid inducedUC animal models confirmed by antioxidant and antiinflammatory activities. Also, the protective effect of Omega-3 on colonic tissues might be mediated by adjustment of inflammatory mediators and increasing antioxidants as well as attenuating oxidant/antioxidant imbalance. Moreover, Omega-3 administration may have anti-apoptotic effect and increasing proliferation of colon cells.

\section{ACKNOWLEDGEMENT}

I wish to thank Prof. Shawky A.A. Moustafa, Pathology Dept., Fac. Vet. Med., Benha Univ. for his great assistance in performing the histopathological examination of colon samples, taking the histopathological photos and recording its reports.

\section{REFERENCES}

1. Abdeslam-Ait, A. (2019): Direct Submission. Submitted (11Akcan, A., Kucuk, C., Sozuer, E., Esel, D., Akyildiz, H., Akgun, H., \&Aritas, Y., 2008. Melatonin reduces bacterial 
translocation and apoptosis in trinitrobenzenesulphonic acidinduced colitis of rats. World journal of gastroenterology. WJG14(6), 918.

2. Aksit, D., Aksit, H., Yildiz, O., Dogru, M. S., Yay, A. H., Baykalir, B. G., \&Atessahin, A., 2016. Protective effect of 2aminoethyl diphenylborinate in rat colitis model induced by acetic acid. International Journal of Clinical \& Experimental Medicine 9(3)

3. Balas, L., Guichardant, M., Durand, T., \&Lagarde, M., 2014.Confusion between protectin D1 (PD1) and its isomer protectin DX (PDX). An overview on the dihydroxydocosatrienes described to date. Biochimie 99, 1-7.

4. Banerjee, S., Ghosh, S., Sinha, K., Chowdhury, S., \&Sil, P. C., 2019. Sulphur dioxide ameliorates colitis related pathophysiology and inflammation. Toxicology 412, 63-78.

5. Bannenberg, G., \&Serhan, C. N., 2010. Specialized proresolving lipid mediators in the inflammatory response: an update. BiochimicaetBiophysicaActa (BBA)-Molecular and Cell Biology of Lipids 1801(12), 1260-1273.

6. Bancroft, J.D. and Stevens, S.A., 1996. Theory and Practice of Histological Techniques. Churchill-Livingstone, New York. 435-470.

7. Bastaki, S. M., Al Ahmed, M. M., Al Zaabi, A., Amir, N., \& Adeghate, E., 2016. Effect of turmeric on colon histology, body weight, ulcer, IL-23, MPO and glutathione in aceticacid-induced inflammatory bowel disease in rats. BMC complementary and alternative medicine16(1),72.

8. Boobalan, G., Dileep, R., Rani, M. U., Kumar, C. S., Kumar, M. V., \& Reddy, A. G., 2015. Protective role of curcumin and flunixin against acetic acid- induced inflammatory bowel disease via modulating inflammatory mediators and cytokine profile in rats. Journal of Environmental Pathology. Toxicology and Oncology34(4)

9. Calder, P. C., 2015. Marine omega-3 fatty acids and inflammatory processes: effects, mechanisms and clinical relevance. Biochimica et BiophysicaActa (BBA)-Molecular and Cell Biology of Lipids1851(4), 469-484.

10. Calder, P. C., 2017. Omega-3 fatty acids and inflammatory processes: from molecules to man. Biochemical Society Transactions 45(5), 1105-1115.

11. Calder, P. C., Ahluwalia, N., Albers, R., Bosco, N., BourdetSicard, R., Haller, \&Moreines, J., 2013. A consideration of biomarkers to be used for evaluation of inflammation in human nutritional studies. British Journal of Nutrition109(S1),S1-S34.

12. Chipuk, J. E., Moldoveanu, T., Llambi, F., Parsons, M. J., \& Green, D. R., 2010. The BCL-2 family reunion. Molecular cell 37(3), 299-310.

13. Cho, J. Y., Chi, S. G., \& Chun, H. S., 2011. Oral administration of docosahexaenoic acid attenuates colitis induced by dextran sulfate sodium in mice. Molecular nutrition \& food research55(2), 239-246.

14. Diab, J., Al-Mahdi, R., Gouveia-Figueira, S., Hansen, T., Jensen, E., Goll, R., ... \& Forsdahl, G., 2018. A quantitative analysis of colonic mucosal oxylipins and endocannabinoids in treatment-naïve and deep remission ulcerative colitis patients and the potential link with cytokine gene expression. Inflammatory bowel diseases 25(3), 490-497.

15. Dogan, Z., Ergul, B., Sarikaya, M., Filik, L. E. V. E. N. T., Gonultas, M. A., Hucumenoglu, S., Can, M., 2014.The antioxidant effect of Echinacea angustifolia and Echinacea purpurea in rat colitis model induced by acetic acid. Bratislavskelekarskelisty 115(7), 411-415.

16. El-Akabawy, G., \& El-Sherif, N. M., 2019.Zeaxanthin exerts protective effects on acetic acid-induced colitis in rats via modulation of pro-inflammatory cytokines and oxidative stress. Biomedicine \& Pharmacotherapy111,841-851.

17. Farrukh, A., \& Mayberry, J. F., 2014. Is there a role for fish oil in inflammatory bowel disease?. World Journal of Clinical Cases.WJCC 2(7), 250

18. Ghalwash, A. M., Soliman, N. A., Hamouda, H. E., \& Absakhron, S. A., 2017. Effects of N-acetylcysteine on acetic- acid-induced ulcerative colitis in experimental rat model. Tanta Medical Journal 45(1), 36.

19. Glorieux, C., \& Calderon, P. B.,2017.Catalase, a remarkable enzyme: targeting the oldest antioxidant enzyme to find a new cancer treatment approach. Biological chemistry 398(10), 1095-1108.

20. Hamabata, T., Nakamura, T., Masuko, S., Maeda, S., \& Murata, T., 2018. Production of lipid mediators across different disease stages of dextran sodium sulfate-induced colitis in mice. Journal of lipid research 59(4), 586-595

21. Hartmann, R. M., Martins, M. I. M., Tieppo, J., Fillmann, H. S., \&Marroni, N. P., 2012. Effect of Boswelliaserrata on antioxidant status in an experimental model of colitis rats induced by acetic acid. Digestive diseases and sciences 57(8), 2038-2044.

22. Hosseini, M. J., Motaghi, E., Ghasemi-Pirbaluti, M., Najafi, A., \&Minaiyan, M., 2017.Effect of salbutamol against the experimental acute colitis in rat model. Comparative Clinical Pathology 26(3), 591-598.

23. Hosseinzadeh, F., Salehi, M., Tanideh, N., Mehrabani, D., Sayarifard, A., \&Sedighi, A., 2017. The Healing effect of grape seed oil enema with or without sesame oil in acetic acid induced ulcerative colitis of rats. World journal of plastic surgery6(2), 176 .

24. Kandhare, A. D., Patil, A., Guru, A., Mukhrjee, A., Sarkar, A., Sengupta, A., ... \& Bodhankar, S. L., 2016. Ameliorative effect of ferulic acid against acetic acid induced ulcerative colitis: Role of HO-1 and Nrf2. Pharmacologia 7, 114-124.

25. Karakoyun, B., Ertaş, B., Yüksel, M., Akakın, D., Çevik, Ö.,\&Sener, G.,2018. Ameliorative effects of riboflavin on acetic acid-induced colonic injury in rats. Clinical and Experimental Pharmacology and Physiology45(6),563-572.

26. Khodayar, B., Farzaei, M. H., Abdolghaffari, A. H., Bahramsoltani, R., Baeeri, M., SabbaghZiarani, F., \&Abdollahi, M., 2018. The Protective effect of the gallic acid against tnbs-induced ulcerative colitis in rats: role of inflammatory parameters. Journal of Iranian Medical Council 1(1), 34-42.

27. Klebanoff, S. J., Kettle, A. J., Rosen, H., Winterbourn, C. C., \& Nauseef, W. M., 2013. Myeloperoxidase: a front-line defender against phagocytosed microorganisms. Journal of leukocyte biology 93(2), 185-198.

28. Kountouras, J., Kouklakis, G., Zavos, C., Chatzopoulos, D., Moschos, J., Molyvas, E., \& Zavos, N., 2003. Apoptosis, inflammatory bowel disease and carcinogenesis: Overview of international and Greek experience. Canadian Journal of Gastroenterology and Hepatology 17(4), 249-258.

29. Kumar, V. L., Pandey, A., Verma, S., \& Das, P., 2019. Protection afforded by methanol extract of Calotropisprocera latex in experimental model of colitis is mediated through inhibition of oxidative stress and pro-inflammatory signaling. Biomedicine \& Pharmacotherapy109,1602-1609.

30. Labib, D. A. A., Shaker, O. G., \& Elfarouk, L. O., 2016. Protective effects of nebivolol on acetic acid-induced ulcerative colitis in rats. Kasr Al Ainy Medical Journal 22(3), 99

31. MacPherson, B. R., \& Pfeiffer, C. J., 1978. Experimental production of diffuse colitis in rats. Digestion17(2),135-150.

32. Marcon, R., Bento, A. F., Dutra, R. C., Bicca, M. A., Leite, D. F., \&Calixto, J. B., 2013. Maresin 1, a proresolving lipid mediator derived from omega-3 polyunsaturated fatty acids, exerts protective actions in murine models of colitis. The Journal of Immunology191(8), 4288-4298.

33. Marion-Letellier, R., Savoye, G., \&Ghosh, S.,2015. Polyunsaturated fatty acids and inflammation. IUBMB life 67(9), 659-667.

34. Martnon, F., Mayor, A., \&Tchopp, J., 2009.The inflammasomes: guardians of the body. Annu. Rev. Immunol 27, 229-265.

35. Masoodi, M., Pearl, D. S., Eiden, M., Shute, J. K., Brown, J. F., Calder, P. C., \&Trebble, T. M., 2013. Altered colonic mucosal polyunsaturated fatty acid (PUFA) derived lipid 
mediators in ulcerative colitis. new insight into relationship with disease activity and pathophysiology. PLoSOne8(10), e76532.

36. Mesbah, L.; Soraya, B.; Narimane, S. and Jean, P.F.,2004. protective effect of flavonides against the toxicity of vinblastine cyclophosphamide and paracetamol by inhibition of lipid-peroxydation and increase of liver glutathione. Haematol 7 (1),59-67.

37. Michalak, A., Mosińska, P., \&Fichna, J., 2016. Polyunsaturated fatty acids and their derivatives: therapeutic value for inflammatory, functional gastrointestinal disorders, and colorectal cancer. Frontiers in pharmacology 7, 459.

38. Molodecky NA, Soon IS, Rabi DM, et al., 2012. Increasing incidence and prevalence of the inflammatory bowel diseases with time, based on systematic review. Gastroenterology142(1), 46-54.

39. Ola, M. S., Nawaz, M., \& Ahsan, H., 2011. Role of Bcl-2 family proteins and caspases in the regulation of apoptosis. Molecular and cellular biochemistry 351, 41-58.

40. Orrenius, S., Gogvadze, V., \&Zhivotovsky, B.,2007. Mitochondrial oxidative stress: implications for cell death. Annu. Rev. Pharmacol. Toxicol 47, 143-183.

41. Ozturk, C. C., Oktay, S., Yuksel, M., Akakin, D., Yarat, A., \&KasimayCakir, O.,2015. Anti-inflammatory effects of nesfatin-1 in rats with acetic acid-induced colitis and underlying mechanisms. J Physiol Pharmacol 66(5),741-50.

42. Paget, G. E., \& Barnes, J. M.,1964. Toxicity tests. Evaluation of drug activities: Pharmacometrics 1,135-65.

43. Patterson, J.W. and Lazarow, A., 1955.Determination of glutathione. Methods of Biochemical Analysis 2, 259-278.

44. Qiu, L., Yin, G., Cheng, L., Fan, Y., Xiao, W., Yu, G., Xing, M., Jia, R., Sun, R., Ma, X., Hu, G., Wang, X., Tang, M., Zhao, Y.,2015. Astragaloside IV ameliorates acute pancreatitis in rats by inhibiting the activation of nuclear factor-kappa B. Int J Mol Med 35, 625-636.

45. Rezayat, S. M., Dehpour, A. R., Motamed, S. M., Yazdanparast, M., Chamanara, M., Sahebgharani, M., \& Rashidian, A., 2018. Foeniculumvulgare essential oil ameliorates acetic acid-induced colitis in rats through the inhibition of NF-kB pathway. Inflammopharmacology 26(3), 851-859.

46. Saber, S., Khalil, R. M., Abdo, W. S., Nassif, D., \& ElAhwany, E., 2019. Olmesartanameliorates chemicallyinduced ulcerative colitis in rats via modulating NF- $x \mathrm{~B}$ and Nrf-2/HO-1 signaling crosstalk. Toxicology and applied pharmacology 364,120-132.

47. Salmena, L., Lemmers, B., Hakem, A., Matysiak-Zablocki, E., Murakami, K., Au, P. B., ... \& Wakeham, A., 2003. Essential role for caspase 8 in T-cell homeostasis and T-cell-mediated immunity. Genes \& development 17(7), 883-895.

48. Sanchez-Muñoz, F., Dominguez-Lopez, A., \& YamamotoFurusho, J. K.,2008. Role of cytokines in inflammatory bowel disease. World journal of gastroenterology: WJG14(27), 4280.

49. Sarosiek, K. A., Fraser, C., Muthalagu, N., Bhola, P. D., Chang, W., McBrayer, S. K., ... \& Deng, J., 2017. Developmental regulation of mitochondrial apoptosis by cMyc governs age-and tissue-specific sensitivity to cancer therapeutics. Cancer Cell 31(1), 142-156.

50. Serhan, C. N., 2010 . Novel lipid mediators and resolution mechanisms in acute inflammation: to resolve or not?. The American journal of pathology 177(4), 1576-1591.

51. Serhan, C. N., Dalli, J., Colas, R. A., Winkler, J. W., \& Chiang, N.,2015. Protectins and maresins: New pro-resolving families of mediators in acute inflammation and resolution bioactive metabolome. Biochimica et Biophysica Acta (BBA)-Molecular and Cell Biology of Lipids 1851(4), $397-$ 413

52. Serhan, C. N., de la Rosa, X, \&Jouvene, C., 2018. Novel mediators and mechanisms in the resolution of infectious inflammation: Evidence for vagus regulation. Journal of internal medicine.

53. Shalkami, A. S., Hassan, M. I. A., \&Bakr, A. G., 2018.Antiinflammatory, antioxidant and anti-apoptotic activity of diosmin in acetic acid-induced ulcerative colitis. Human \& experimental toxicology 37(1), 78-86.

54. Sharma, M., Kaur, R., Kaushik, K., \& Kaushal, N., 2019 Redox modulatory protective effects of $\omega$-3 fatty acids rich fish oil against experimental colitis. Toxicology mechanisms and methods 29(4), 244-254.

55. Sierra, S., Lara-Villoslada, F., Comalada, M., Olivares, M. \&Xaus, J., 2008. Dietary eicosapentaenoic acid and docosahexaenoic acid equally incorporate as decosahexaenoic acid but differ in inflammatory effects. Nutrition 24(3), 245254.

56. Singh, R., Letai, A., \& Sarosiek, K., 2019. Regulation of apoptosis in health and disease: the balancing act of BCL-2 family proteins. Nature Reviews Molecular Cell Biology, 1.

57. Soliman, N. A., Keshk, W. A., Rizk, F. H., \& Ibrahim, M. A. 2019. The possible ameliorative effect of simvastatin versus sulfasalazine on acetic acid induced ulcerative colitis in adult rats. Chemico-biological interactions 298, 57-65.

58. Tatiya-aphiradee, N., Chatuphonprasert, W., \&Jarukamjorn, K. , 2017. Induction of Colitis in Experimental Animals: A Review. Isan Journal of Pharmaceutical Sciences 13(4), 1-10.

59. Tekeli, İ. O., Ateşşahin, A., Sakin, F., Aslan, A., Çeribaşı, S., \& Yipel, M., 2018. Protective effects of conventional and colon-targeted lycopene and linalool on ulcerative colitis induced by acetic acid in rats. Inflammopharmacology 5, 1-10.

60. Triantafyllidis, I., Poutahidis, T., Taitzoglou, I., Kesisoglou, I., Lazaridis, C., \&Botsios, D. , 2015.Treatment with Mesna and n-3 polyunsaturated fatty acids ameliorates experimental ulcerative colitis in rats. International journal of experimental pathology 96(6), 433-443.

61. Tyagi, A., Kumar, U., Reddy, S., Santosh, V. S., Mohammed, S. B., Ehtesham, N. Z., \& Ibrahim, A., 2012. Attenuation of colonic inflammation by partial replacement of dietary linoleic acid with $\alpha$-linolenic acid in a rat model of inflammatory bowel disease. British Journal of Nutrition 108(9), 1612-1622.

62. Wallace, K. L., Zheng, L. B., Kanazawa, Y., \& Shih, D. Q., 2014. Immunopathology of inflammatory bowel disease. World journal of gastroenterology: WJG 20(1), 6 .

63. Weldon, S. M., Mullen, A. C., Loscher, C. E., Hurley, L. A., \& Roche, H. M., 2007. Docosahexaenoic acid induces an antiinflammatory profile in lipopolysaccharide-stimulated human THP-1 macrophages more effectively than eicosapentaenoic acid. Journal of nutritional biochemistry 18(4), 250-258.

64. Xu, J.B.; Yuan, X.F. and Lang, P.Z., 1997.Determination of catalase activity and catalase inhibition by ultraviolet spectrophtometry. Chinee Environ. Chem16,73-76

65. Yates, C. M., Calder, P. C., \&Rainger, G. E., 2014 Pharmacology and therapeutics of omega-3 polyunsaturated fatty acids in chronic inflammatory disease. Pharmacology \& therapeutics 141(3), 272-282. 